\title{
Substituted Dithiobiurets, their Molybdenum and Tungsten Complexes as Corrosion Inhibitors for Mild Steel in Sulphuric Acid
}

\author{
R.B. Rastogi, M. Yadav, K. Singh, M.M. Singh* \\ Department of Applied Chemistry, Institute of Technology \\ Banaras Hindu University, Varanasi - 221005 (INDIA)
}

Received 13 March 2003; accepted in revised form 16 April 2004

\begin{abstract}
The inhibition of mild steel corrosion in $1 \mathrm{~N}$ sulphuric acid was studied in the presence of various concentrations (10-150 ppm) of substituted dithiobiurets and their molybdenum and tungsten complexes at $25{ }^{\circ} \mathrm{C}$. All the compounds behaved as ambiodic corrosion inhibitors for mild steel and were considered to inhibit the corrosion by getting adsorbed on the surface. The inhibition efficiencies (IEs) of the complexes, in general, were found to be appreciably higher than those of corresponding ligands. However, the IE values of the complexes of molybdenum and tungsten of the same ligand did not differ much in their magnitude indicating thereby that the nature of central metal ions hardly influenced the inhibition efficiency. The slight difference in the IEs of the complexes at a given concentration seems to be caused by the slight difference in their size. The variation in IEs of different derivatives of ligands has been attributed to change in their size, number of active sites for adsorption and the electron density on these active sites. Scanning Electron Microscopy was used to study the surface of corroded and inhibited specimens.
\end{abstract}

Keywords: Corrosion inhibition, mild steel, Mo and W complexes.

\section{Introduction}

Mild steel is extensively used as an inexpensive structural material for fabrication of storage tanks, pipe lines, shipping drums etc. These equipments may

\footnotetext{
* Corresponding author. E-mail address: apchemhd@bhu.ac.in
} 
encounter severe attack of sulphuric acid during acid cleaning, pickling, descaling, acidizing in mining and oil wells and also during transportation. The inhibitors employed for such systems are reported to be mainly pure organic compounds containing $\mathrm{N}, \mathrm{O}$ and/or $\mathrm{S}$ as the hetero- donor atoms [1-6]. Few reports [7-8] are available in the literature where the use of naturally occurring substances has been recommended as corrosion inhibitors for this system. More recently study of metal complexes as a new class of corrosion inhibitors for a different system has been successfully accomplished in this laboratory [9-13] and it has been invariably found that complexation of an organic base results in increased inhibition efficiency.

In view of the above, a few dithiobiurets and their molybdenum and tungsten complexes have been synthesized and their inhibitive properties have been studied for mild steel $-1.0 \mathrm{~N}$ sulphuric acid system. Further, attempt has been made to correlate the IEs of different inhibitors with their structures.

\section{Experimental}

The working electrode and specimens for weight loss and electrochemical experiments were prepared from mild steel sheets having the following percentage composition:

$\begin{array}{ccccccccc}\mathrm{C} & \mathrm{Mn} & \mathrm{Si} & \mathrm{P} & \mathrm{S} & \mathrm{N} & \mathrm{Cu} & \mathrm{Cr} & \mathrm{Fe} \\ 0.12 & 0.11 & 0.02 & 0.02 & 0.02 & 0.02 & 0.01 & 0.01 & \text { Remainder }\end{array}$

The specimens for the weight loss experiments were of the size $3 \times 3 \mathrm{~cm}$ and those for electrochemical studies the size of the electrodes was $1 \times 1 \mathrm{~cm}$ with a $4 \mathrm{~cm}$ long tag for electrochemical contact. Both sides of the specimens were exposed for both the techniques. The specimens were mechanically polished successively with $1 / 0,2 / 0,3 / 0$ and 4/0 grade emery papers. After polishing with the paper of each grade, the surface was thoroughly washed with soap, running tap water, distilled water and finally was degreased with acetone. The samples were dried and stored in a vacuum desiccator before immersing in the test solution. For 
weight loss experiments $300 \mathrm{~mL}$ of $1 \mathrm{~N} \mathrm{H}_{2} \mathrm{SO}_{4}$ were taken in $500 \mathrm{~mL}$ glass beakers with lids. The inhibition efficiencies were evaluated after $24 \mathrm{~h}$ using 10 , 20, 50, 100 and $150 \mathrm{ppm}$ of inhibitors. The specimens were removed from the electrolyte, washed thoroughly with distilled water, dried and weighed.

The electrochemical experiments were carried out in a three necked glass assembly containing $150 \mathrm{~mL}$ of the electrolyte with different concentrations of inhibitors (from $10 \mathrm{ppm}$ to $150 \mathrm{ppm}$ by weight) dissolved in it. Polarisation studies were performed in unstirred undaerated solutions using a Wenking Potentiostat (POS-73). Starting from open circuit potential, the potential was manually applied in $10 \mathrm{mV}$ steps in the anodic or cathodic direction and the corresponding steady state currents were measured directly from the ammeter on the panel of potentiostat. All experiments were performed at $25 \pm 2{ }^{\circ} \mathrm{C}$ in an electronically controlled air thermostat.

The inhibitors 1-aryl-2,4 dithiobiurets were prepared [14] by refluxing aryl amines and isoperthionic acid in ethanol for half an hour. The metal complexes of the dithiobiurets were prepared by mixing an acidified aqueous solution of sodium molybdate/tungstate and an ethanolic solution of the corresponding ligand in approximately 1:1 molar ratio. After digesting the reaction mixture on water bath, the precipitate obtained was filtered, washed with hot water, followed by ethanol and dried in vacuo [15].

\section{Results and Discussion}

The percentage inhibition efficiencies (\%IE) of different dithiobiurets i.e. phenyl-, $p$-methylphenyl-, $p$-methoxyphenyl- and $p$-chlorophenyl- derivatives at 10, 20, 50, 100 and $150 \mathrm{ppm}$ have been evaluated by weight loss and electrochemical techniques, at $25^{\circ} \mathrm{C}$ and the results are recorded in Table 1 . The percentage inhibition efficiency (\% IE) of the inhibitors has been evaluated by using the equation

$$
\% I E=\frac{w-w_{i}}{w} \times 100
$$


where $\mathrm{w}$ is weight loss in uninhibited solution, and $\mathrm{w}_{\mathrm{i}}$ is weight loss in inhibited solution.

Table 1. Percentage inhibition efficiency (\% IE) values calculated by weight loss and polarisation techniques in the presence of dithiobiurets and their $\mathrm{Mo}(\mathrm{V})$ and $\mathrm{W}(\mathrm{V})$ complexes

\begin{tabular}{|c|c|c|c|c|c|c|}
\hline \multirow{2}{*}{$\begin{array}{c}\text { Concentration } \\
\text { ppm }\end{array}$} & \multicolumn{2}{|c|}{ Ligand } & \multicolumn{2}{|c|}{$\mathrm{Mo}(\mathrm{V})$ Complex } & \multicolumn{2}{|c|}{$\mathrm{W}(\mathrm{V})$ Complex } \\
\hline & $\begin{array}{l}\text { Weight } \\
\text { loss } \\
\text { method }\end{array}$ & $\begin{array}{l}\text { Polarisation } \\
\text { method }\end{array}$ & $\begin{array}{l}\text { Weight } \\
\text { loss } \\
\text { method }\end{array}$ & $\begin{array}{c}\text { Polarisation } \\
\text { method }\end{array}$ & $\begin{array}{l}\text { Weight } \\
\text { loss } \\
\text { method }\end{array}$ & $\begin{array}{c}\text { Polarisation } \\
\text { method }\end{array}$ \\
\hline \multicolumn{7}{|c|}{ 1-phenyl-2,4-dithiobiuret } \\
\hline 10 & 65.11 & 64.21 & 72.34 & 70.86 & 76.12 & 75.10 \\
\hline 20 & 71.43 & 69.94 & 82.32 & 81.12 & 85.32 & 84.16 \\
\hline 50 & 75.52 & 74.12 & 88.12 & 87.16 & 90.16 & 88.10 \\
\hline 100 & 81.16 & 76.86 & 92.24 & 90.92 & 94.24 & 93.15 \\
\hline 150 & 83.18 & 82.22 & 93.26 & 92.16 & 95.12 & 94.26 \\
\hline \multicolumn{7}{|c|}{ 1-p-methylphenyl-2,4-dithiobiuret } \\
\hline 10 & 67.52 & 66.12 & 75.36 & 74.12 & 78.21 & 76.84 \\
\hline 20 & 72.12 & 70.96 & 85.42 & 84.16 & 88.16 & 86.93 \\
\hline 50 & 76.33 & 75.13 & 92.48 & 91.32 & 95.12 & 93.84 \\
\hline 100 & 82.13 & 80.98 & 95.38 & 94.24 & 97.12 & 96.13 \\
\hline 150 & 86.18 & 85.22 & 96.46 & 95.16 & 98.42 & 98.11 \\
\hline \multicolumn{7}{|c|}{ 1-p-methoxyphenyl-2,4-dithiobiuret } \\
\hline 10 & 70.12 & 69.82 & 80.24 & 78.84 & 83.48 & 83.12 \\
\hline 20 & 76.24 & 75.32 & 88.31 & 86.92 & 90.47 & 89.16 \\
\hline 50 & 79.34 & 78.12 & 94.48 & 93.12 & 95.34 & 94.26 \\
\hline 100 & 85.11 & 83.74 & 98.12 & 97.16 & 98.31 & 96.15 \\
\hline 150 & 88.14 & 87.31 & 99.31 & 98.24 & 99.86 & 98.16 \\
\hline \multicolumn{7}{|c|}{ 1-p-chlorophenyl-2,4-dithiobiuret } \\
\hline 10 & 58.44 & 56.92 & 65.12 & 64.24 & 67.42 & 66.24 \\
\hline 20 & 60.16 & 58.14 & 68.36 & 67.12 & 71.34 & 70.32 \\
\hline 50 & 65.18 & 64.22 & 76.16 & 74.86 & 78.24 & 77.43 \\
\hline 100 & 70.12 & 68.93 & 79.24 & 78.16 & 81.12 & 80.21 \\
\hline 150 & 74.31 & 73.16 & 81.24 & 80.13 & 82.34 & 81.34 \\
\hline
\end{tabular}


For evaluating percentage inhibition efficiency electrochemically $\mathrm{w}$ and $\mathrm{w}_{\mathrm{i}}$ in the above equation were replaced by $I$ and $I_{i n h}$, respectively. I and $I_{\text {inh }}$ represent the corrosion current densities (determined by Tafel extrapolation method) in the absence and presence of inhibitors, respectively. The data recorded in Table 1 show that the inhibition efficiencies calculated by electrochemical method are in good agreement with those calculated from the weight loss data within the limits of the experimental error.

It is further evident from these data that all the inhibitors are good inhibitors even at the concentration as low as $10 \mathrm{ppm}$. On increasing the concentration of the inhibitors from $10 \mathrm{ppm}$ to $150 \mathrm{ppm}$ the \% IE increases gradually and linearly. The structure of the inhibitors molecules are shown below:

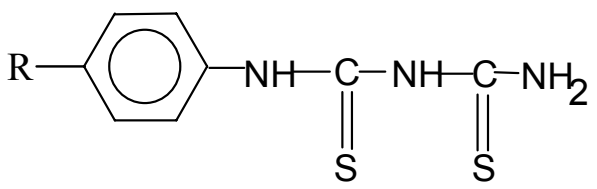

where

$$
\begin{aligned}
& \mathrm{R}=-\mathrm{H}, 1-\text { phenyl-2,4-dithiobiuret, Inh I } \\
& \mathrm{R}=-\mathrm{CH}_{3}, 1-p \text {-methylphenyl-2,4-dithiobiuret, Inh II } \\
& \mathrm{R}=-\mathrm{OCH}_{3}, 1-p \text {-methoxyphenyl-2,4-dithiobiuret, Inh III } \\
& \mathrm{R}=-\mathrm{Cl}, 1-p-\text { chlorophenyl-2,4-dithiobiuret, Inh IV }
\end{aligned}
$$

On the basis of \% IE afforded by these inhibitors at their different concentrations, the inhibitors can be arranged in the following sequence:

$$
\text { Inh III }>\text { Inh II }>\text { Inh I }>\text { Inh IV }
$$

The effectiveness of these inhibitors may be explained assuming the potential dependent adsorption as the cause of the inhibition. The extent of adsorption of different inhibitors at a fixed concentration would depend upon the surface area of the inhibitor molecules, the number of active centres such as $\mathrm{N}, \mathrm{S}$ and $\mathrm{O}$ atoms and the intensities of lone pairs of electrons on these sites along with the intensities of $\pi$-electrons on aromatic rings. 
The percentage inhibition efficiency exhibited by these inhibitors is high and is supposed to be due to strong adsorption of the inhibitor molecules on the metal surface thereby preventing corrosion of mild steel in sulphuric acid solution. The inhibitor is expected to get adsorbed through the lone pairs of electrons on $\mathrm{N}$ and $\mathrm{S}$ atoms as well as $\pi$-electron density on the phenyl ring by their coordination with the metal surface. The participation of phenyl ring in addition to that of $\mathrm{N}$ and $\mathrm{S}$ atoms during the adsorption process may be confirmed by changing the $\pi$ electron density on phenyl ring. The substitution by an electron donating group such as $-\mathrm{CH}_{3}$, on the phenyl ring may cause an increase in the $\pi$-electron density and as a consequence the \% IE is expected to increase. A further increase in \% IE was found when $-\mathrm{CH}_{3}$ group was replaced by $-\mathrm{OCH}_{3}$ group. This enhancement in inhibition is due to better electron donating property of the methoxy group as compared to that of methyl group.

The participation of $\pi$-electrons of the phenyl ring during adsorption is further confirmed on replacing electron donating groups by an electron withdrawing group like -chloro group. It is observed during the investigation that the substitution of these groups resulted in a decrease in inhibition efficiencies. The decrease in \% IE due to the presence of -chloro group has been reported earlier [16].

The percentage inhibition efficiencies of molybdenum and tungsten dithiobiuret complexes have been evaluated at 10,20,50,100 and $150 \mathrm{ppm}$ concentrations at $25{ }^{\circ} \mathrm{C}$ and the data are recorded in Table 1 . The observed trend in case of the complexes remains the same as that observed in the case of the respective ligands. The representative structure of the metal complex is shown below:

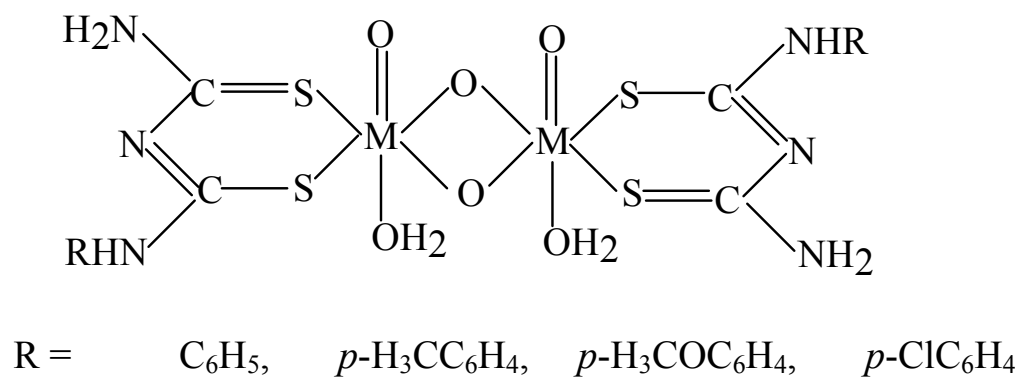




$$
\begin{array}{rllll}
\text { For M= Mo(V) } & \operatorname{Inh}(\mathrm{V}) & \operatorname{Inh}(\mathrm{VI}) & \operatorname{Inh}(\mathrm{VII}) & \operatorname{Inh}(\mathrm{VIII}) \\
\mathrm{M}=\mathrm{W}(\mathrm{V}) & \operatorname{Inh}(\mathrm{IX}) & \operatorname{Inh}(\mathrm{X}) & \operatorname{Inh}(\mathrm{XI}) & \operatorname{Inh}(\mathrm{XII})
\end{array}
$$

It is clear from the structure of the complexes that these have larger size and more active sites of adsorption than the corresponding ligands. Hence, the metal complexes show higher \% IE than the corresponding ligands. In the case of complexes, the \% IE is high even at very low concentrations. The \% IE observed in the case of metal complexes of various ligands follows the same trend as that followed by the respective ligands.

It is also observed that the \% IE of the complexes of molybdenum and tungsten of the same ligand does not differ much in their magnitude. Thus, the nature of metal atoms may be considered to have no significant role in corrosion inhibition of mild steel in sulphuric acid. The \% IE of the complexes of both Mo and W are nearly the same due to similar structures of both the complexes and also due to having the same number of active sites. The small variation in \% IE may be attributed to the small difference in their size.

Anodic polarization behaviour of mild steel in $1 \mathrm{~N} \mathrm{H}_{2} \mathrm{SO}_{4}$ containing 20, 50, 100 and $150 \mathrm{ppm}$ of Inh I is shown in Fig. 1. It is to be noted that the nature of the curve for the blank solution is not affected by the addition of the inhibitor or subsequent increase in its concentration. Almost similar nature of the polarization curves, both in the absence and presence of the inhibitor, indicates that there is no change in the mechanism of corrosion on the addition of the inhibitor to the electrolyte [17]. However, the curves in the presence of the inhibitor gradually shifted towards lower current density side in the whole range of the potential studied. For the addition of $20 \mathrm{ppm}$ of the inhibitor an appreciable decrease in current density at each potential is observed which, however, further decreases very slowly on subsequent addition of the inhibitor. The relative shift in the position of the curves at different concentrations of the inhibitor appears to be in accordance with the \% IE of the inhibitor at that particular concentration. With the other derivatives of the dithiobiuret also, the same trend was observed and therefore the plots are not being mentioned. The lowering of the current density 
at each potential may be due to increase in the polarization resistance caused by the adsorbed inhibitor molecules at the anodic sites [18].

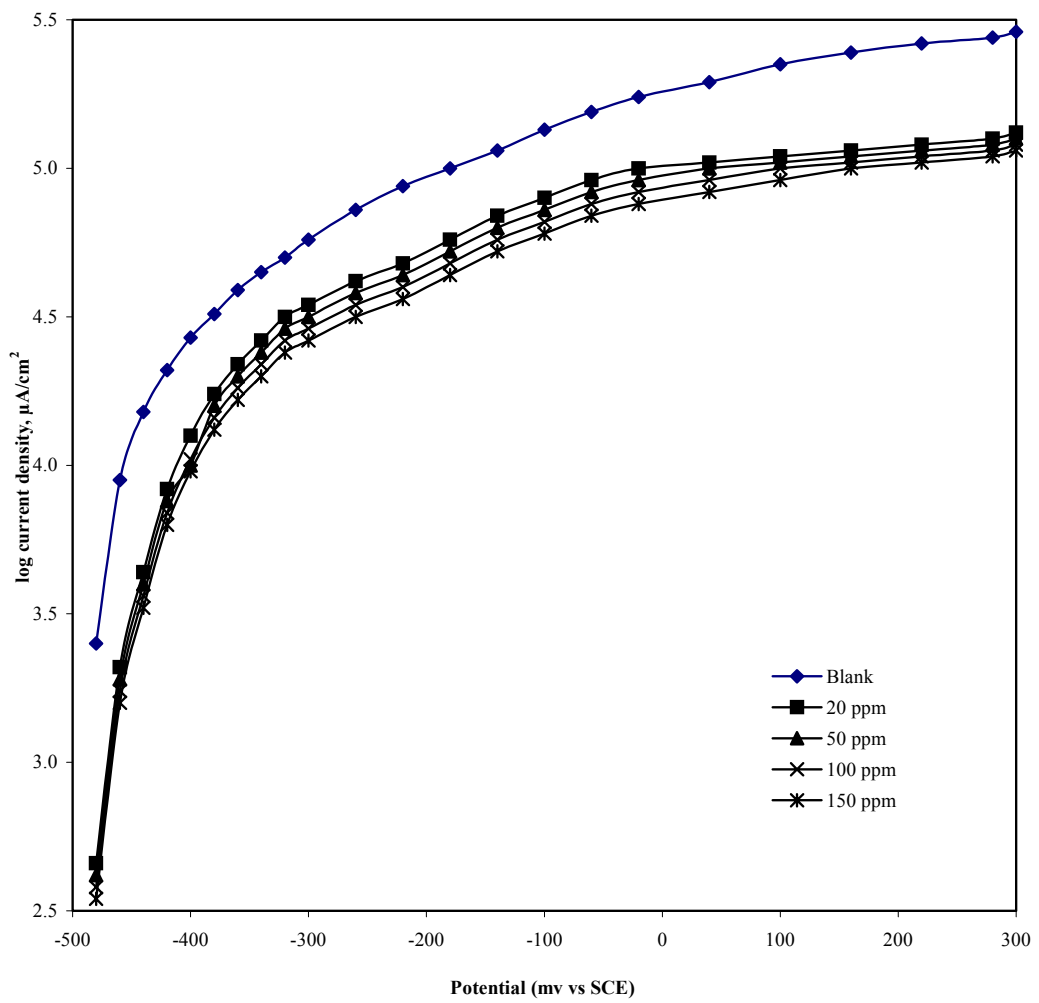

Figure 1. Anodic polarization behaviour of mild steel in $1.0 \mathrm{~N}-\mathrm{H}_{2} \mathrm{SO}_{4}$ in the absence and presence of different concentrations of Inh I at $25^{\circ} \mathrm{C}$.

The anodic polarization curves for all inhibitors i.e. Inh I, Inh II, Inh III and Inh IV studied at $25^{\circ} \mathrm{C}$ at a fixed concentration of $150 \mathrm{ppm}$ have been illustrated in Fig. 2. The observed shift in the anodic polarization curves due to each of the inhibitors follows the same trend as that followed by their inhibition efficiencies. Thus, it may be inferred that inhibitors are effective at local anode by getting adsorbed. Maximum shift towards lower current density is observed for Inh III which shows maximum \% IE whereas minimum shift is observed for Inh IV which shows minimum \% IE.

The anodic polarization behaviour of mild steel in $1.0 \mathrm{~N} \mathrm{H}_{2} \mathrm{SO}_{4}$ containing 20, 50, 100 and 150 ppm of Inh $\mathrm{V}$ is shown in Fig. 3. It may be noted that the anodic polarization curves for the complex are similar to the curves obtained in the presence of respective ligand and in the blank solution, showing that there is no change in the mechanism of corrosion on the addition of the complex to 


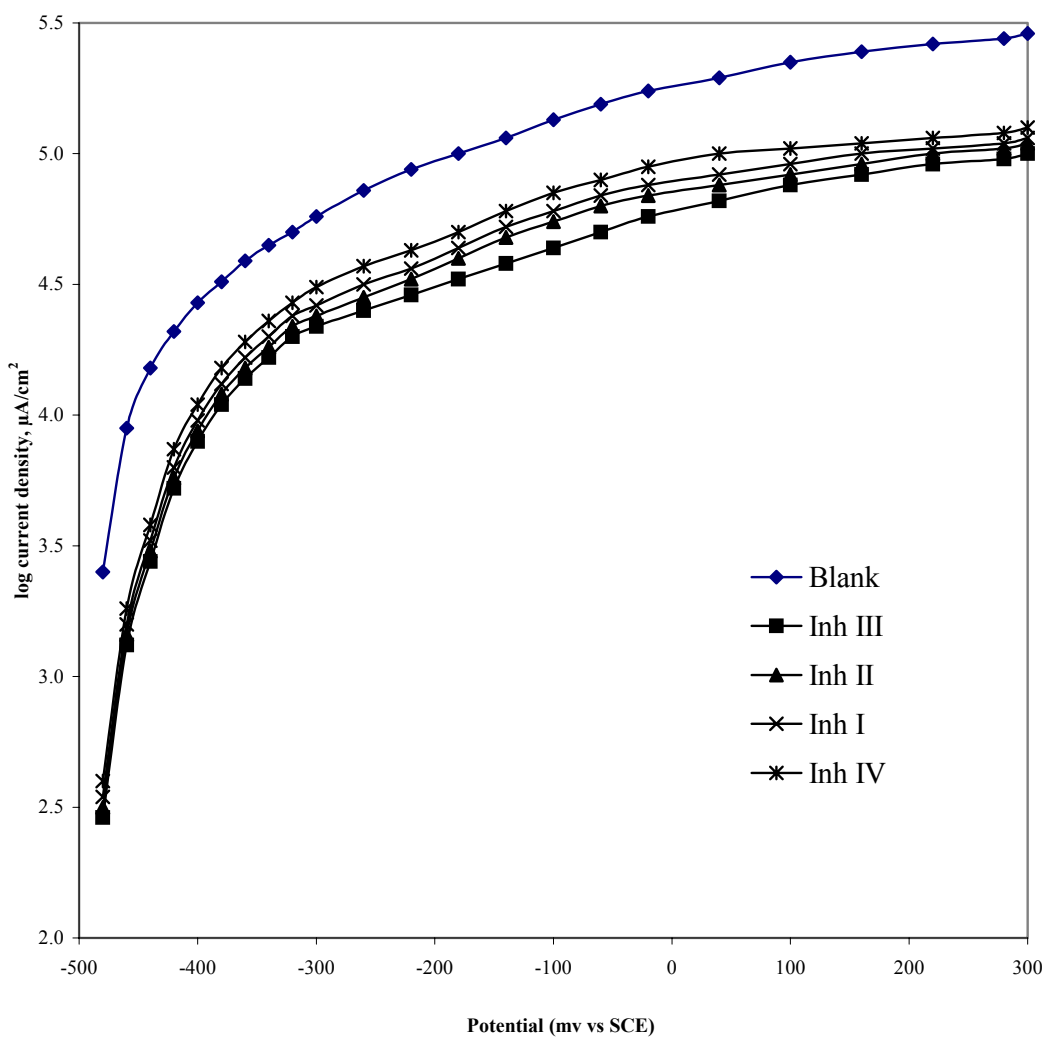

Figure 2. Anodic polarization behaviour of mild steel in $1.0 \mathrm{~N}-\mathrm{H}_{2} \mathrm{SO}_{4}$ in the absence and presence of $150 \mathrm{ppm}$ of Inh I, Inh II, Inh III AND Inh IV at $25^{\circ} \mathrm{C}$.

the electrolyte. However, the shift towards lower current density in case of the complex is larger than the corresponding ligand indicating that Mo complex is more effective as an inhibitor than the corresponding ligand.

The anodic polarisation curves in the presence of molybdenum complexes of all the derivatives of dithiobiuret at $25^{\circ} \mathrm{C}$ at a fixed concentration of $150 \mathrm{ppm}$ have been shown in Fig. 4. All these curves are found to be similar. The Inh VII shows the maximum shift towards lower current density whereas Inh VIII shows the minimum shift. The order of the shift of anodic polarization curves is exactly identical to the sequence of inhibition efficiencies calculated from weight loss method. 


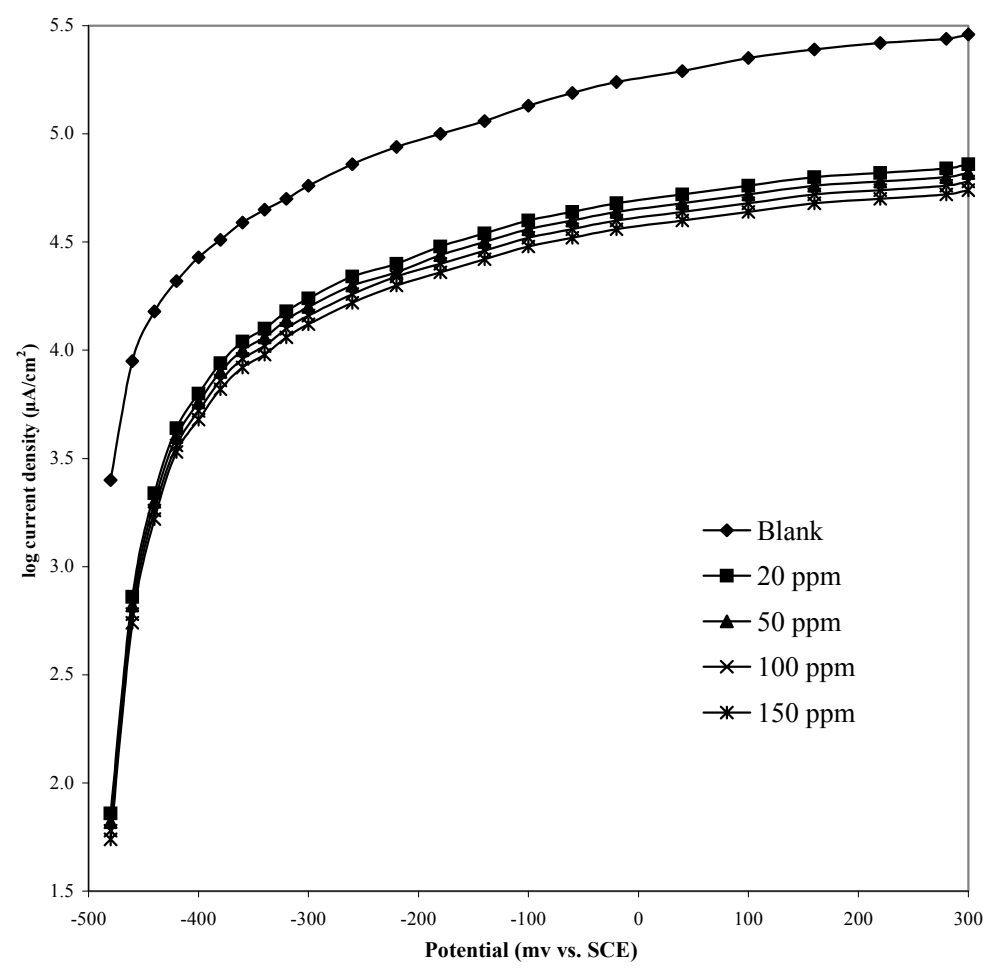

Figure 3. Anodic polarization behaviour of mild steel in $1.0 \mathrm{~N}-\mathrm{H}_{2} \mathrm{SO}_{4}$ in the absence and presence of different concentrations of Inh $\mathrm{V}$ at $25^{\circ} \mathrm{C}$.

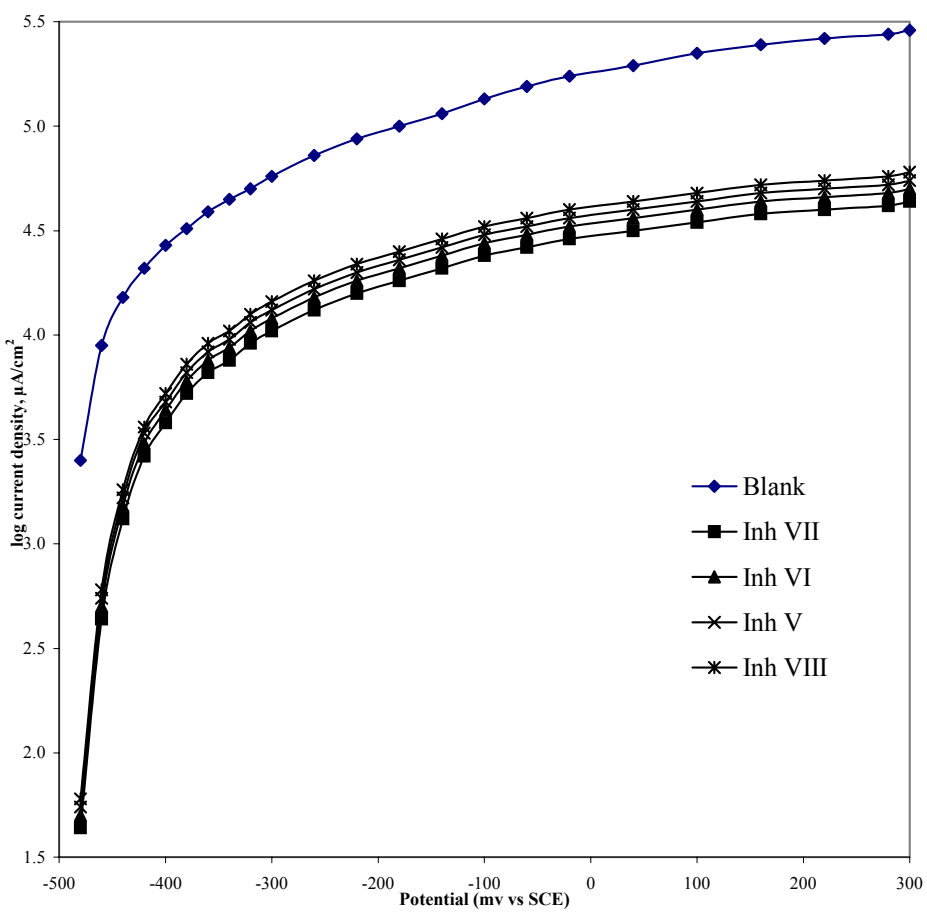

Figure 4. Anodic polarization behaviour of mild steel in $1.0 \mathrm{~N}-\mathrm{H}_{2} \mathrm{SO}_{4}$ in the absence and presence of $150 \mathrm{ppm}$ of Inh V, Inh VI, Inh VII and Inh VIII AT $25{ }^{\circ} \mathrm{C}$. 
Anodic polarization behaviour of tungsten complexes of all the ligands has been studied at the same concentrations as those of molybdenum complexes. Therefore, the polarisation curves of tungsten complexes at some representative concentrations only are being discussed. Fig. 5 shows the anodic polarization behaviour of mild steel in $1 \mathrm{~N} \mathrm{H}_{2} \mathrm{SO}_{4}$ in the presence and absence of 20 and 150 ppm of Inh III, Inh VII and Inh XI. The curves show that tungsten complexes also exhibit similar nature of anodic curve as that observed in case of the ligand and its molybdenum complexes. It is also noticed that the extent of shift of anodic curve in case of molybdenum and tungsten complexes at $150 \mathrm{ppm}$ is nearly the same and at $20 \mathrm{ppm}$ the shift is more in case of tungsten complexes than the molybdenum complexes.

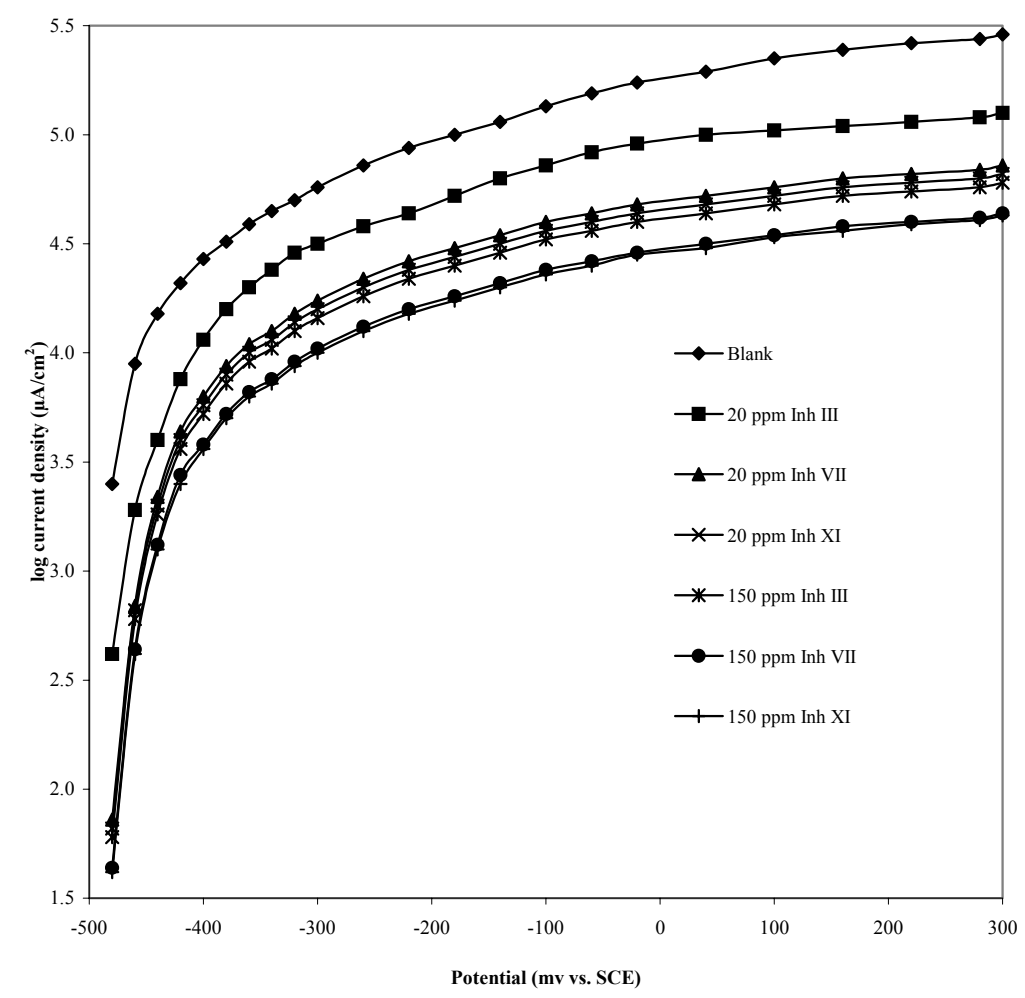

Figure 5. Anodic polarization behaviour of mild steel in $1.0 \mathrm{~N}$ sulphuric acid in the absence and presence of 20 and $150 \mathrm{ppm}$ of Inh III, Inh VII and Inh XI at $25{ }^{\circ} \mathrm{C}$.

The shift towards lower current density follows the same order as the \% IE of the ligand and its molybdenum and tungsten complexes calculated by weight loss technique. 
Fig. 6 illustrates the cathodic polarisation curves in the presence of different concentrations of Inh I at $25^{\circ} \mathrm{C}$. It is observed that inhibited curves shift towards lower current density with respect to the uninhibited curve. On increasing the concentration of the inhibitor, the extent of shift towards lower current density increases in a manner very similar to that observed in the case of anodic polarization behaviour. It may be further noted that the cathode is more polarised on addition of a given amount of the inhibitor than the anode.

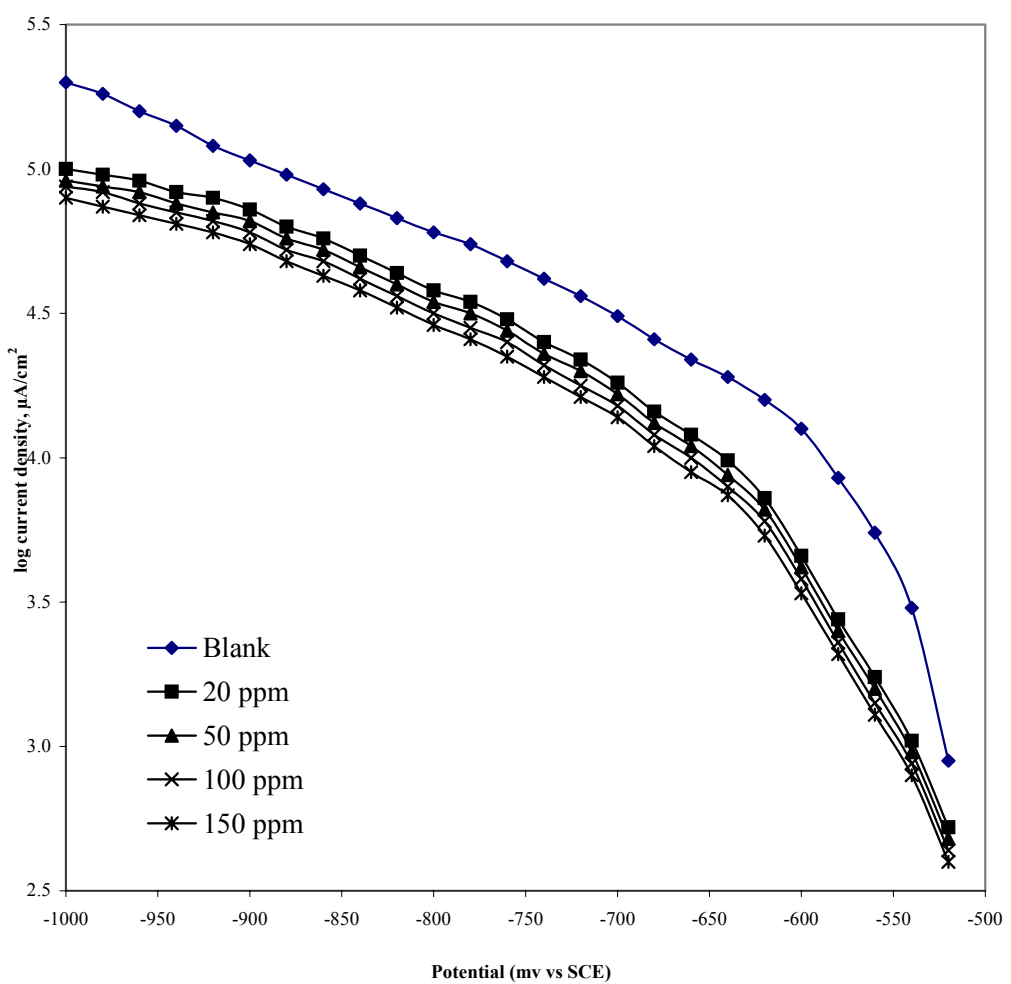

Figure 6. Cathodic polarization behaviour of mild steel in $1.0 \mathrm{~N}-\mathrm{H}_{2} \mathrm{SO}_{4}$ in the absence and presence of different concentrations of Inh I at $25{ }^{\circ} \mathrm{C}$.

The cathodic polarization curves for all derivatives of dithiobiuret at $25{ }^{\circ} \mathrm{C}$ with $150 \mathrm{ppm}$ of inhibitor concentration have been shown in Fig. 7. It is observed that maximum shift towards lower current density is observed for Inh III which shows maximum \% IE and minimum shift is observed for Inh IV with minimum $\%$ IE. 


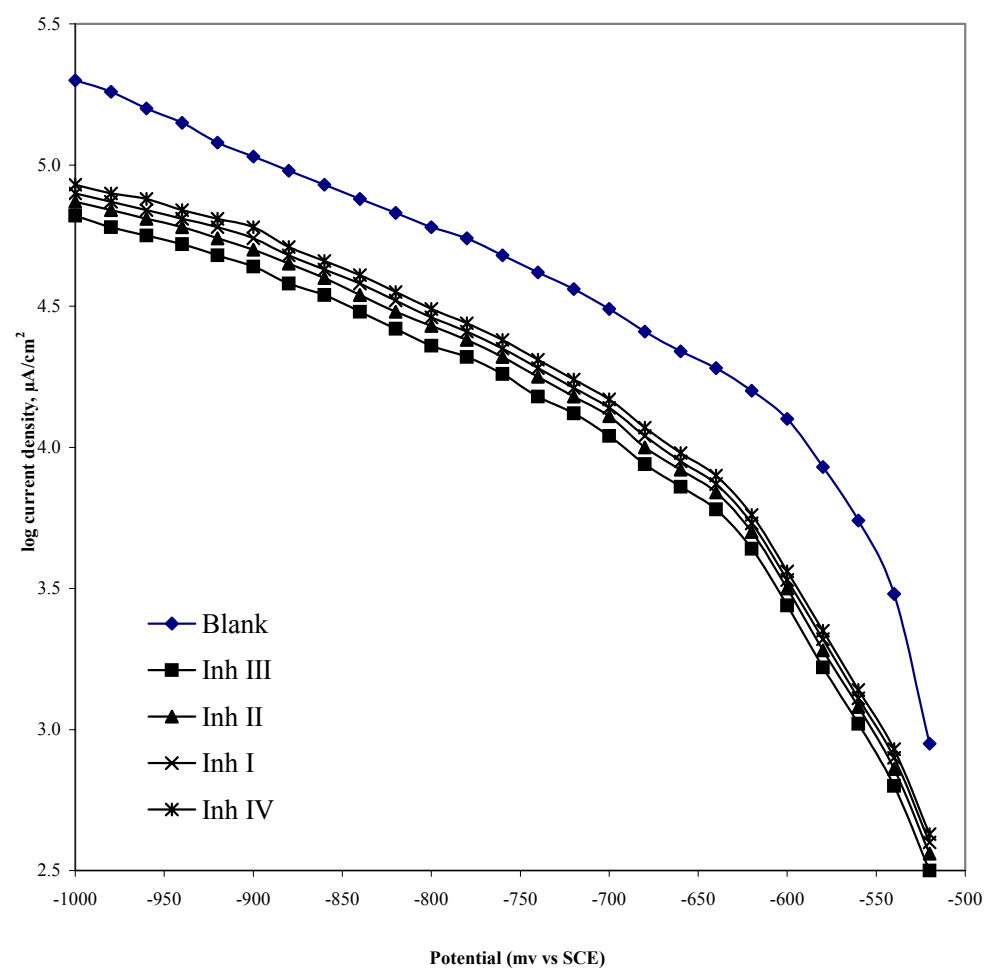

Figure 7. Cathodic polarization behaviour of mild steel in $1.0 \mathrm{~N}-\mathrm{H}_{2} \mathrm{SO}_{4}$ in the absence and presence of $150 \mathrm{ppm}$ of Inh I, Inh II, Inh III and Inh IV AT $25^{\circ} \mathrm{C}$.

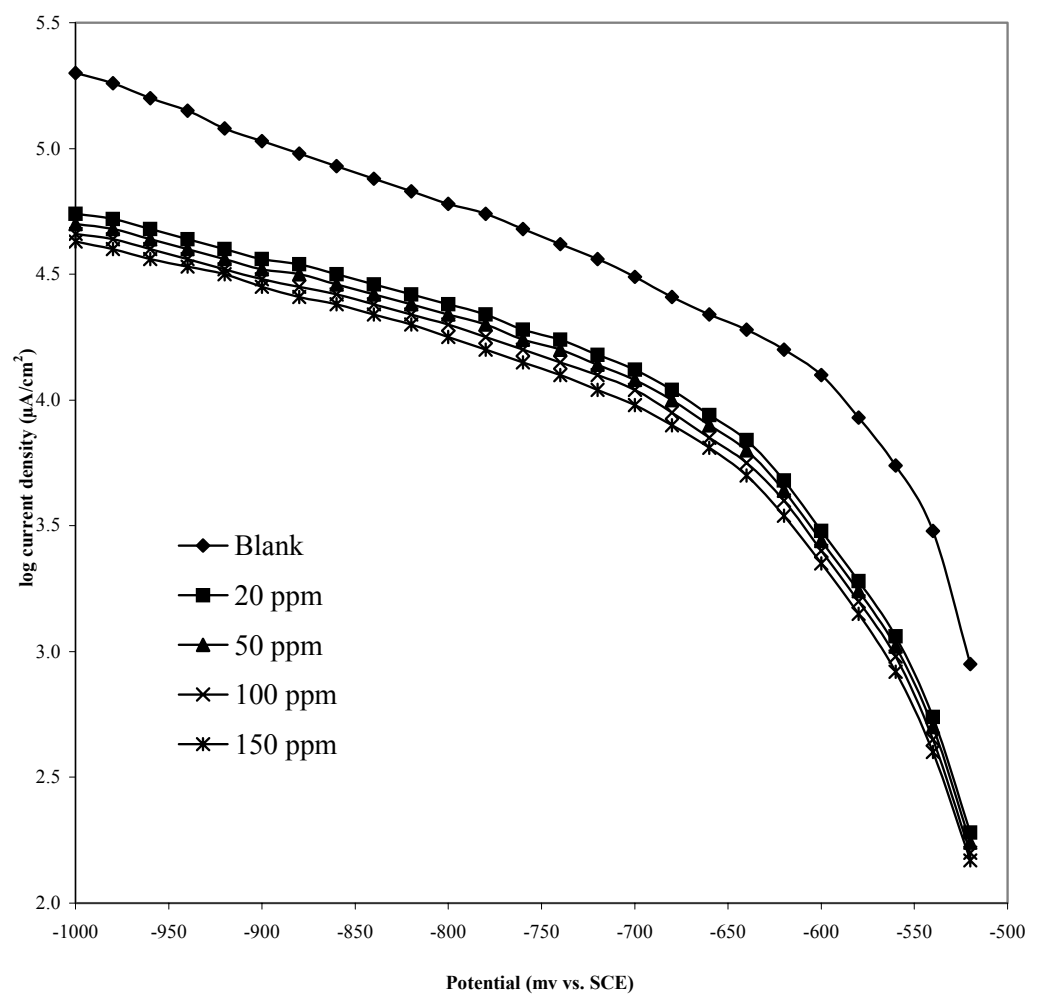

Figure 8. Cathodic polarization behaviour of mild steel in $1.0 \mathrm{~N}-\mathrm{H}_{2} \mathrm{SO}_{4}$ in the absence and presence of different concventrations of Inh $\mathrm{V}$ at $25^{\circ} \mathrm{C}$. 
Fig. 8 shows the cathodic polarisation curves in the presence of different concentrations of Inh $\mathrm{V}$ at $25{ }^{\circ} \mathrm{C}$. It is observed that the inhibited curves shifted towards lower current density and the magnitude of the shift in this case is more than that due to Inh I. The cathodic polarisation curves for molybdenum complexes of all the ligands at $25{ }^{\circ} \mathrm{C}$ at a fixed concentration of $150 \mathrm{ppm}$ are shown in Fig. 9. It is observed again that the shift towards lower current density in these curves is greater as compared to the corresponding ligands. The maximum shift towards lower current density is exhibited by Inh VII which exhibits maximum \% IE.

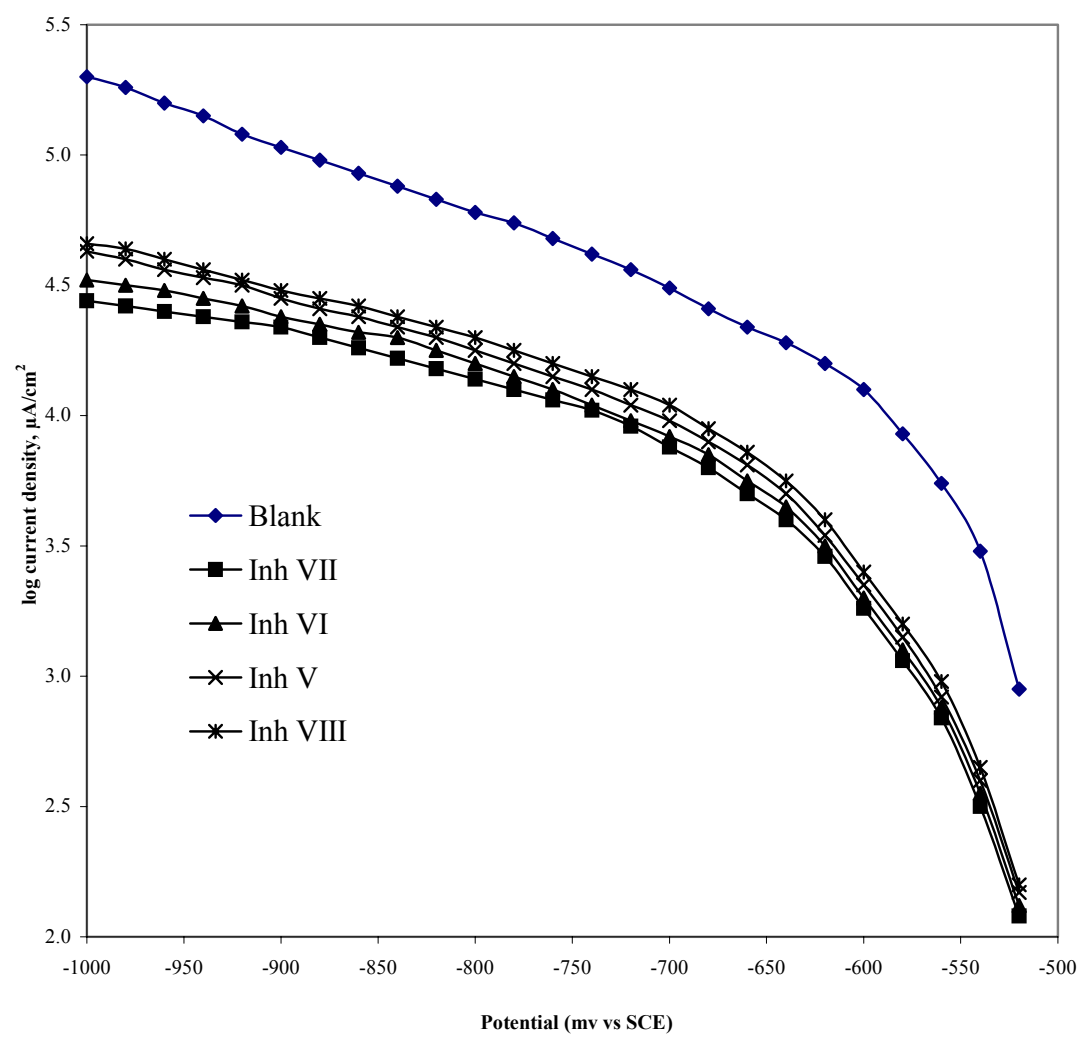

Figure 9. Cathodic polarization behaviour of mild steel in $1.0 \mathrm{~N}-\mathrm{H}_{2} \mathrm{SO}_{4}$ in the absence and presence of $150 \mathrm{ppm}$ of Inh V, Inh VI, Inh VII and Inh VIII at $25^{\circ} \mathrm{C}$.

Fig. 10 shows the comparison of the extent of shift of cathodic curves towards lower current density for Inh III, Inh VII and Inh XI at 20 and 150 ppm concentration at $25{ }^{\circ} \mathrm{C}$. It is observed that the shift in curves follow the same trend as the anodic polarisation curve for the same compounds. The extent of 
shift towards lower current density follows the same order as the \% IE of these compounds calculated by the weight loss method.

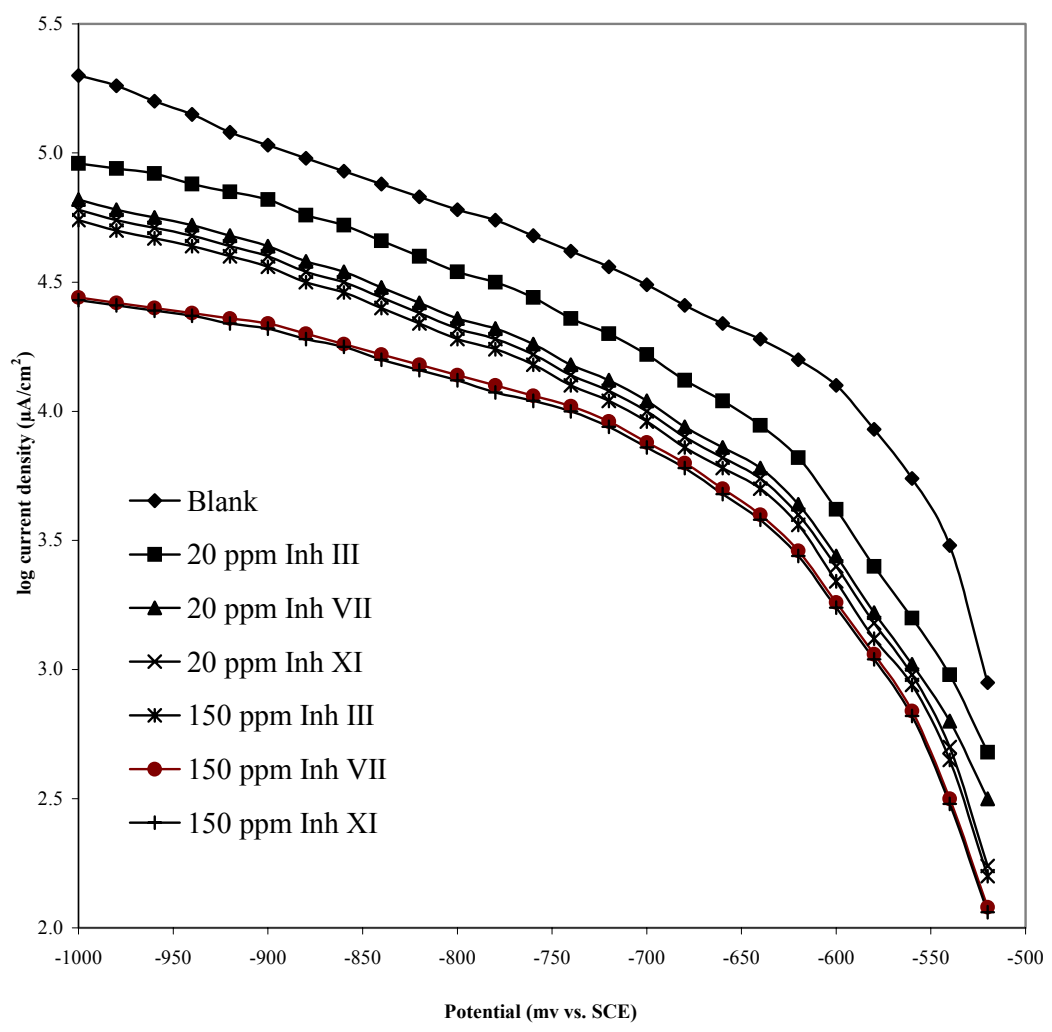

Figure 10. Cathodic polarization behaviour of mild steel in $1.0 \mathrm{~N}$ sulphuric acid in the absence and presence of 20 and $150 \mathrm{ppm}$ of Inh III, Inh VII and Inh XI at $25^{\circ} \mathrm{C}$.

The adsorption of inhibitor molecules on the surface of the corroding metal has been considered as the root cause of corrosion inhibition. Assuming that the percentage area covered by the inhibitors is directly proportional to retardation in the corrosion rate, the compounds should obey either the Langmuir or those of Temkin or Frumkin [19]. The experimental equation of Frumkin isotherm [20, $21]$ is

$$
\theta / 1-\theta \exp (\mathrm{f} \theta)=\mathrm{KC}
$$

where ' $\mathrm{K}$ ' is the equilibrium constant for the adsorption reaction and ' $\mathrm{C}$ ' is the concentration of the inhibitor in mole litre ${ }^{-1}$. ' $\theta$ ' is the degree of coverage and ' $\mathrm{f}$ ' is a parameter connected with the variation of adsorption energy with coverage. 
Langmuir isotherm is obtained for $\mathrm{f}=0$ and may be written as

$$
\log \frac{\theta}{1-\theta}=\log \mathrm{A}+\log \mathrm{C}-\frac{\mathrm{Q}}{2.3 \mathrm{RT}}
$$

where $\mathrm{A}$ and $\mathrm{Q}$ are temperature independent constant and heat of adsorption, respectively. The validity of Langmuir isotherm is confirmed from the linearity of the $\log (\theta /(1-\theta))$ vs. $\log C$ plot having the slope value to be unity. The plots of $\log (\theta /(1-\theta))$ vs. $\log \mathrm{C}$ for the investigated substituted dithiobiurets, their molybdenum and tungsten complexes at $25{ }^{\circ} \mathrm{C}$ are shown in Figs. 11 to 13 , respectively. It is observed that although these plots are linear, the gradients are never unity, contrary to what is expected for the ideal Langmuir adsorption isotherm equation. The departure in the values of the slopes of Langmuir plots from unity may be advocated to be due to the mutual interaction between adsorbed molecules in a close vicinity. Organic molecules and metal complexes having polar atoms or groups which are adsorbed on the metal surface may interact by mutual repulsion or attraction and hence may affect the heat of adsorption.

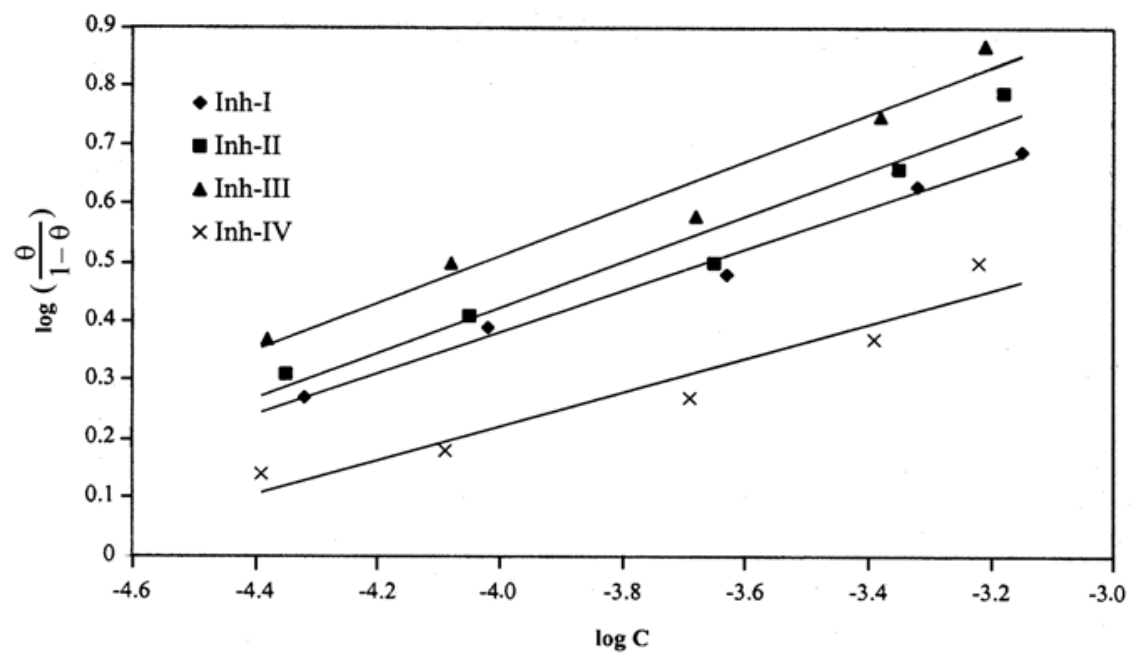

Figure 11. Langmuir plots for substituted dithiobiurets in $1.0 \mathrm{~N}$ sulphuric acid. 


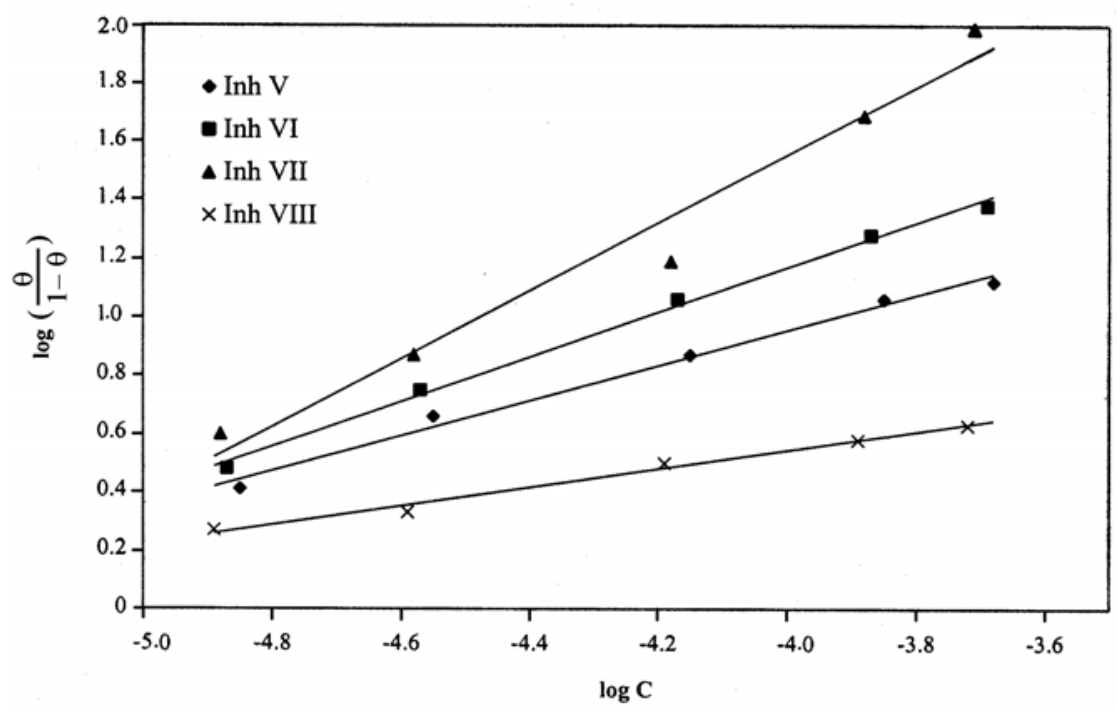

Figure 12. Langmuir plots for $\mathrm{Mo}(\mathrm{V})$ complexes of substituted dithiobiurets in $1.0 \mathrm{~N}$ sulphuric acid.

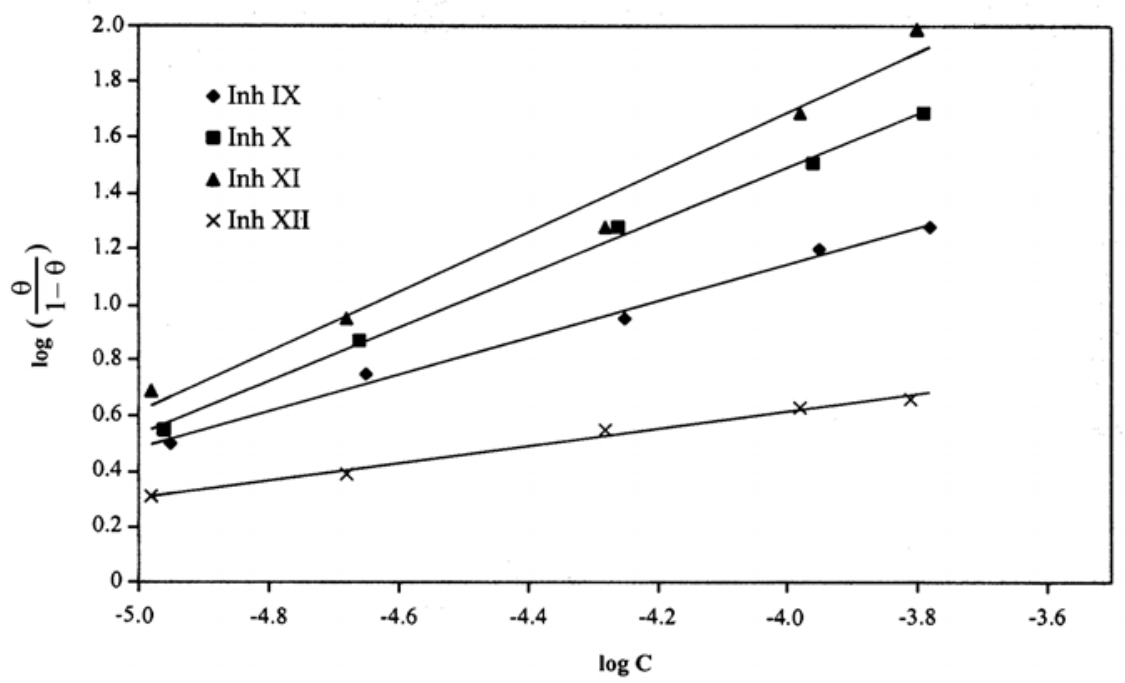

Figure 13. Langmuir plots for $\mathrm{W}(\mathrm{V})$ complexes of substituted dithiobiurets in $1.0 \mathrm{~N}$ sulphuric acid.

The plots of $\theta$ vs. $\log \mathrm{C}$ for the investigated substituted dithiobiurets and their molybdenum and tungsten complexes show a linear relationship, indicating the validity of Temkin's isotherm Figs. 14 to 16. Thus, the adsorption of these inhibitors obey Langmuir as well as Temkin's adsorption isotherms. Similar result has been obtained for several inhibitors for $\mathrm{Cu}-\mathrm{Aq}$. $\mathrm{NaCl}$ system [11]. 


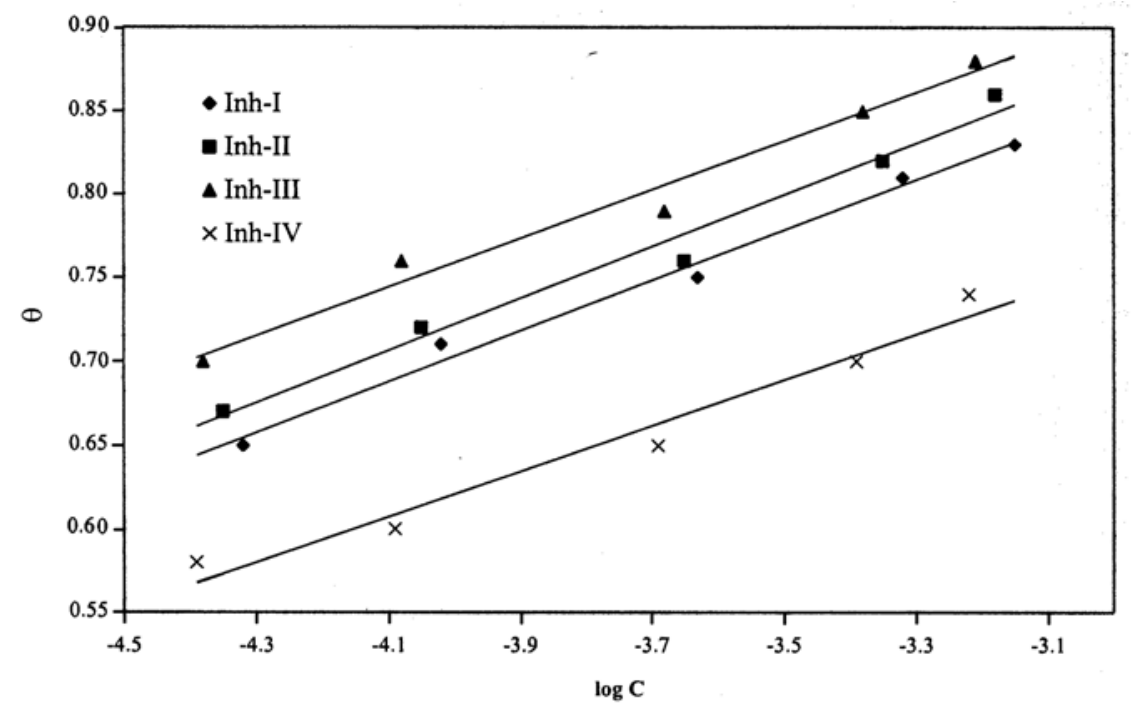

Figure 14. Temkin plots for substituted dithiobiurets in $1.0 \mathrm{~N}$ sulphuric acid.

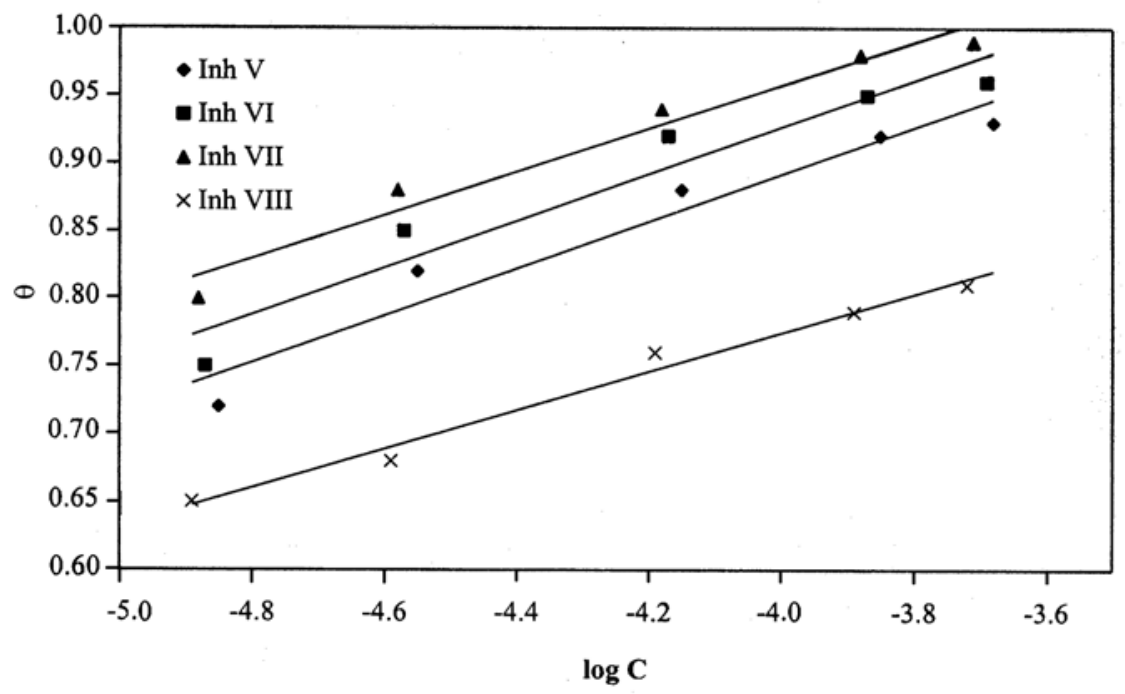

Figure 15. Temkin plots for $\mathrm{Mo}(\mathrm{V})$ complexes of substituted dithiobiurets in $1.0 \mathrm{~N}$ sulphuric acid.

Figs. 17 and 18 show SEM photomicrographs for mild steel in $1.0 \mathrm{~N}$ sulphuric acid solution in the absence and presence of $150 \mathrm{ppm}$ of molybdenum complex of 1-p-methoxyphenyl-2,4-dithiobiuret. On comparing these photomicrographs it appears that in the presence of the inhibitor, the surface of the test material has improved remarkably with respect to its smoothness. The smoothening of the surface would have been caused by the deposition of inhibitor molecules on it and thus the surface is fully covered. 


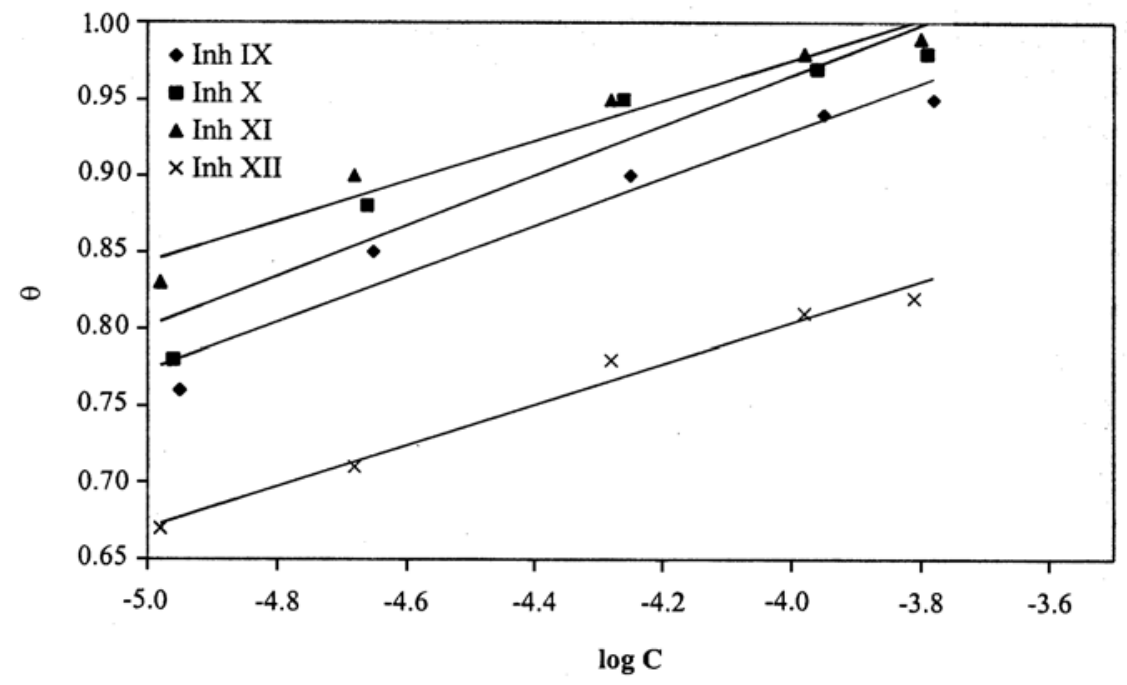

Figure 16. Temkin plots for $\mathrm{W}(\mathrm{V})$ complexes of substituted dithiobiurets in $1.0 \mathrm{~N}$ sulphuric acid.

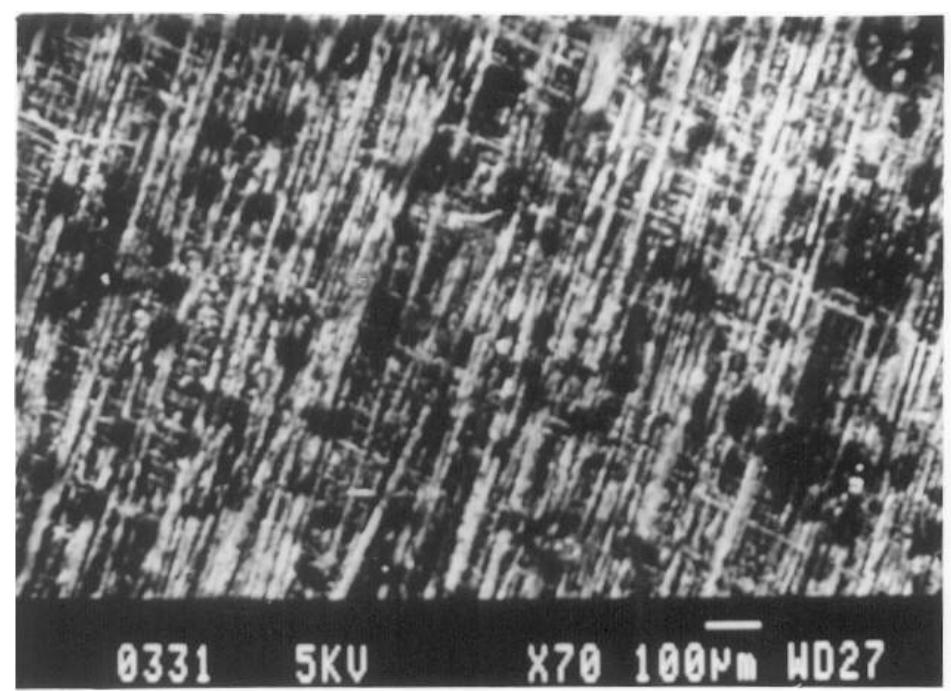

Figure 17. SEM photomicrograph of corroded surface of mild steel in $1.0 \mathrm{~N}$ sulphuric acid.

\section{Conclusions}

1. All the inhibitors used influence both the anodic and cathodic reactions and are thus, ambiodic inhibitors.

2. The inhibition efficiency of dithiobiurets depends on the nature of the substituents. These groups generally affect the electron density on one or other 
active sites through inductive effect.

3. Mo and $\mathrm{W}$ complexes are better inhibitors than the substituted dithiobiurets.

4. Mo and $\mathrm{W}$ complexes provide almost equal inhibition indicating insignificant role played by the nature of central metal ion.

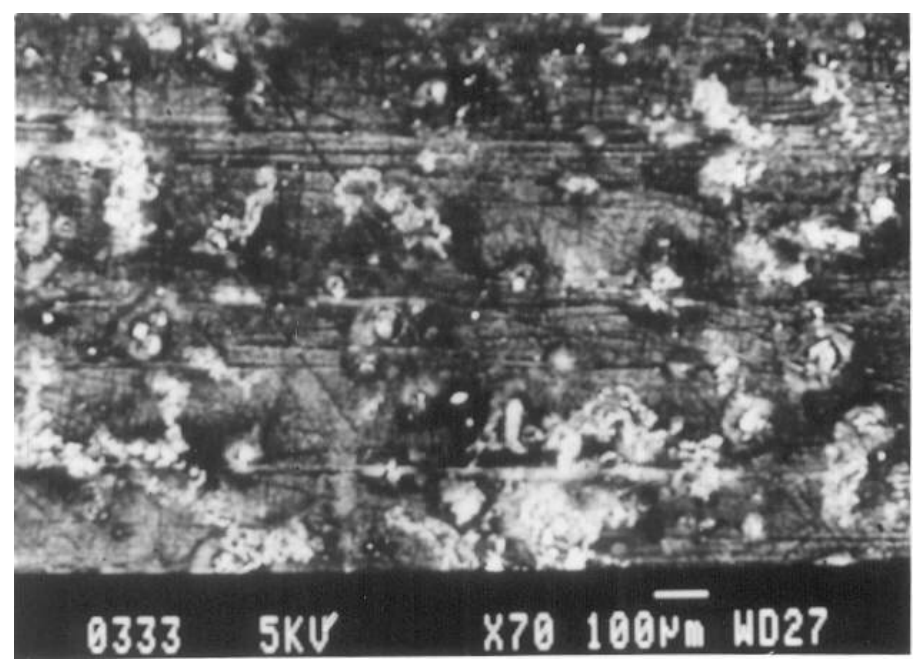

Figure 18. SEM photomocrograph of inhibited surface of mild steel in the presence of $150 \mathrm{ppm}$ of Inh VII in $1.0 \mathrm{~N}$ sulphuric acid.

\section{References}

1. J.L. Jha, G. Singh, Trans. SAEST 26(2-3) (1991) 158.

2. R.K. Chaturvedi, R.S. Chaudhary, Anticorros. Methods \& Mater. 41-05 (1994) 3.

3. G. Moretti, G. Quartarone, A. Tassan, A. Zingales, Electrochim. Acta 41-13 (1996) 1971A.

4. R.S. Chaudhary, S. Sharma, Trans. SAEST 32-4 (1997) 99.

5. S. Sharma, R. Arora, R.S. Chaudhary, J. Electrochem. Soc. India 48-3 (1999) 283.

6. E. Sherbini, Mater. Chem. Phys. 60-3 (1999) 286.

7. Smita, A. Verma, G.N. Mehta, Trans. SAEST 32(2-3) (1997) 58.

8. Smita, A. Verma, G.N. Mehta, Trans. SAEST 33(2-3) (1998) 60. 
9. M.M. Singh, R.B. Rastogi, B.N. Upadhyay, Corrosion 50 (1994) 620.

10. M.M. Singh, R.B. Rastogi, B.N. Upadhyay, Bull. Electrochem. 12(1-2) (1996) 26.

11. M.M. Singh, R.B. Rastogi, B.N. Upadhyay, M. Yadav, Indian J. Chem. Technol. 6 (1999) 93.

12. R.B. Rastogi, M.M. Singh, M.Yadav, K. Singh, Indian J. Eng. Mater. Sci. $10(2003) 155$.

13. R.B. Rastogi, M.M. Singh, M. Yadav, Bull. Electrochem. 20-1 (2004) 19.

14. R. Singh, Chemistry of $N \& S$ Heterocyclic Compounds and Related Systems, Ph.D. Thesis, Banaras Hindu University, 1978.

15. R.B. Rastogi, M.Yadav, K. Singh, Syn. Reac. Org. Met-Org. Chem. 31-6 (2001) 1011.

16. C. Chakrabarty, M.M. Singh, C.V. Agarwal, British Corros. J. 18 (1983) 107.

17. A. Kumar, S.K. Patnaik, M.M. Singh, Mater. Chem. Phys. 56 (1998) 245.

18. C. Chakrabarty, M.M. Singh, C.V. Agarwal, Corrosion and Control 33-2 (1986) 72 .

19. A. Gupta, M.M. Singh, Port. Electrochim. Acta 17 (1999) 21.

20. B.B. Damaski, A.O. Pictrij, W.W. Batrakov, Adsorpeja Organiczescich Sojedinienijna Electrodach Moskwa ,1968.

21. E. Gileadi, Electrosorption, Plenum Press, New York, 1967. 